\title{
HIDROGEOQUÍMICA Y PRODUCCIÓN DE MANANTIALES EN LAS FORMACIONES PACACUA Y PEÑA NEGRA
}

\author{
Asdrúbal Vargas S. \& Rolando Mora Ch. \\ Escuela Centroamericana de Geología. Apdo. 35-2060 \\ Universidad de Costa Rica. \\ E. Mail: avargas@cariari.ucr.ac.cr
}

(Recibido 1/12/1998; Aceptado 8/9/1999)

\begin{abstract}
The discharge of springs in Pacacua and Peña Negra Formation of Trinidad de Mora and Jericó de Desamparados, Costa Rica, was determined to be approximately 0.4 and $24.41 / \mathrm{min}$. The water of the springs of the Pacacua Formation was classified as calcium-bicarbonate or magnesium-chloride and the water of the springs of the Peña Negra Formation as calcium-bicarbonate or magnesium-bicarbonate. The zones of recharge for the springs were defined in order to protect the groundwater resources in the future.
\end{abstract}

RESUMEN: Por primera vez se investiga la calidad físico-química del agua de varios manantiales de las formaciones Pacacua y Peña Negra, consideradas como rocas no acuíferas y ubicadas al sur de San José. El volumen de agua que aportan es muy importante para varias comunidades, que no disponen de otras fuentes de abastecimiento. Se ha medido la producción de manantiales que afloran en la localidad de Trinidad de Mora y Jericó de Desamparados, obteniéndose valores que oscilan entre 0,4 y 24,4 1/min. Además se procedió a clasificar hidrogeoquímicamente las aguas, las cuales se identifican en el caso de los manantiales ubicados en la Formación Pacacua como bicarbonatadas-cálcicas y cloruradas-magnésicas, y las ubicadas en la Formación Peña Negra como bicarbonatadas-cálcicas y bicarbonatadas-sódicas. Además, se han definido las zonas de recarga de los manantiales, dentro de las cuales se deben llevar a cabo medidas de protección para evitar la contaminación del recurso hídrico subterráneo.

\section{INTRODUCCIÓN}

Las formaciones Pacacua y Peña Negra, las cuales afloran al sur del Valle Central han sido poco estudiadas desde el punto de vista hidrogeológico, debido a que se consideran como constituidas por rocas no acuíferas (Arredondo, 1994). Sin embargo, por motivo de la demanda de agua que generan los complejos habitacionales existentes y futuros, ubicados en el área donde se encuentran dichas formaciones, estas adquieren gran relevancia desde el punto de vista del aprovechamiento de sus recursos hídricos. Por lo tanto, con este trabajo se pretende estudiar la calidad físico-química del agua subterránea, así como la producción de algunos manantiales presentes en estas formaciones. Se han investigado manantiales ubicados al SE de Ciudad Colón y en Jericó de Desamparados (Fig. 1). Los manantiales se han designado de la siguiente manera: P-1, P-2, P-3, P-4, P-5, para los que se encuentran en la Formación Pacacua y PN-1, PN-2, PN-3 y PN-4 para los de la Formación Peña Negra. 
La Formación Pacacua, según Denyer \& Arias (1994), está constituida por brechas, areniscas, tobas y lutitas todas con evidente influencia volcánica, de colores rojo y morado, y con estratificación de centimétrica a métrica. Hernández \& Vargas (1992) describen a nivel microscópico las rocas de esta formación en el sector de Escazú y las clasifican como wackas feldespáticas, arcosas y litarenitas y vulcanoruditas. Las wackas están constituidas por plagioclasas, fragmentos de rocas volcánicas y sedimentarias, óxidos de hierro, cuarzo y epidota, los cuales flotan en una matríz arcillosa. Las arcosas contienen granos formados por plagioclasas, fragmentos de rocas volcánicas, cuarzo, piroxenos y óxidos de hierro. En el caso de las vulcanoruditas, los granos que constituyen el esqueleto corresponden a plagioclasas, fragmentos de roca volcánica, óxidos de hierro, epidotas y arcillas. Alvarado (1982) realizó estudios sedimentológicos de la Formación Pacacua y analizó secciones delgadas provenientes de Brasil de Santa Ana, consideradas como vulcarenitas, cuyos clastos están constituidos por cuarzo (2-7\%), fragmentos volcánicos alterados (25-88\%), plagioclasas (5$25 \%)$ y fragmentos arcillosos, calcedonia (2\%), minerales opacos (1-5\%), englobados en una matriz silícea arcillosa y en ocaciones con cemento de sílice. Denyer \& Arias (1991) señalan la presencia de moldes de bivalvos y gasterópodos.

La Formación Peña Negra, según idem, está constituida por tres unidades. La unidad inferior es una secuencia de areniscas medias y finas, con estratos decimétricos; la sección media está constituida por lutitas y areniscas finas de estratificación centimétrica con minerales de pirita y en la unidad superior se presentan intercalaciones de guijarros y estratos de caliza aislados así como areniscas con mucha influencia volcánica, donde se pueden identificar hasta plagioclasas idiomórficas. Según Hernández \& Vargas (1992) las lutitas de esta unidad están constituidas por granos de cuarzo, plagioclasas, piroxenos, óxidos de hierro, ortosa, clastos volcánicos y caparazones de fósiles, todos ellos flotando en una matriz arcillosa. Alvarado (1982) describe secciones delgadas de roca, entre ellas varias consideradas como lutitas

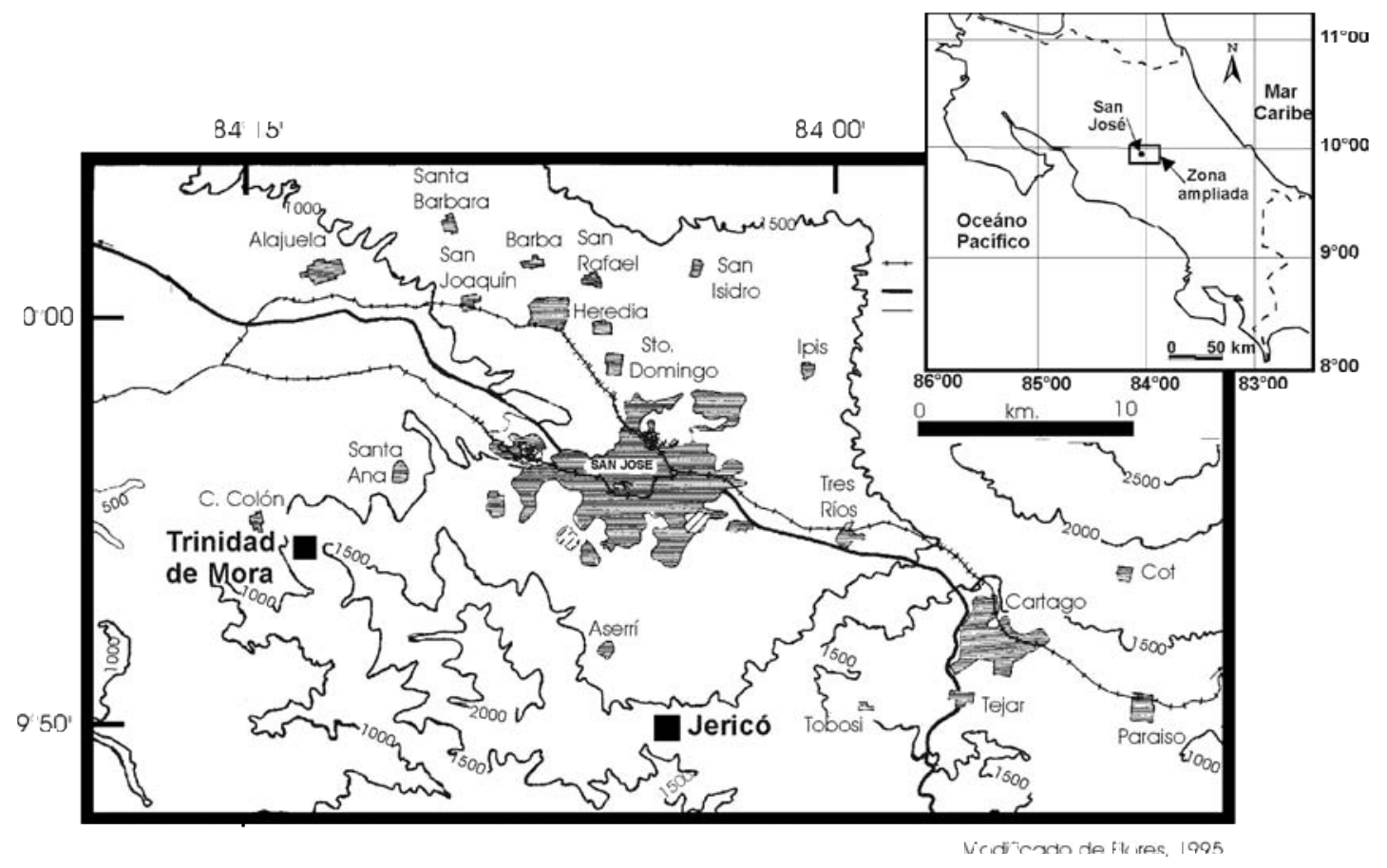

Fig.1: Ubicación de las zonas geográficas en las cuales se encuentran los manantiales, Trinidad de Mora y Jericó. 


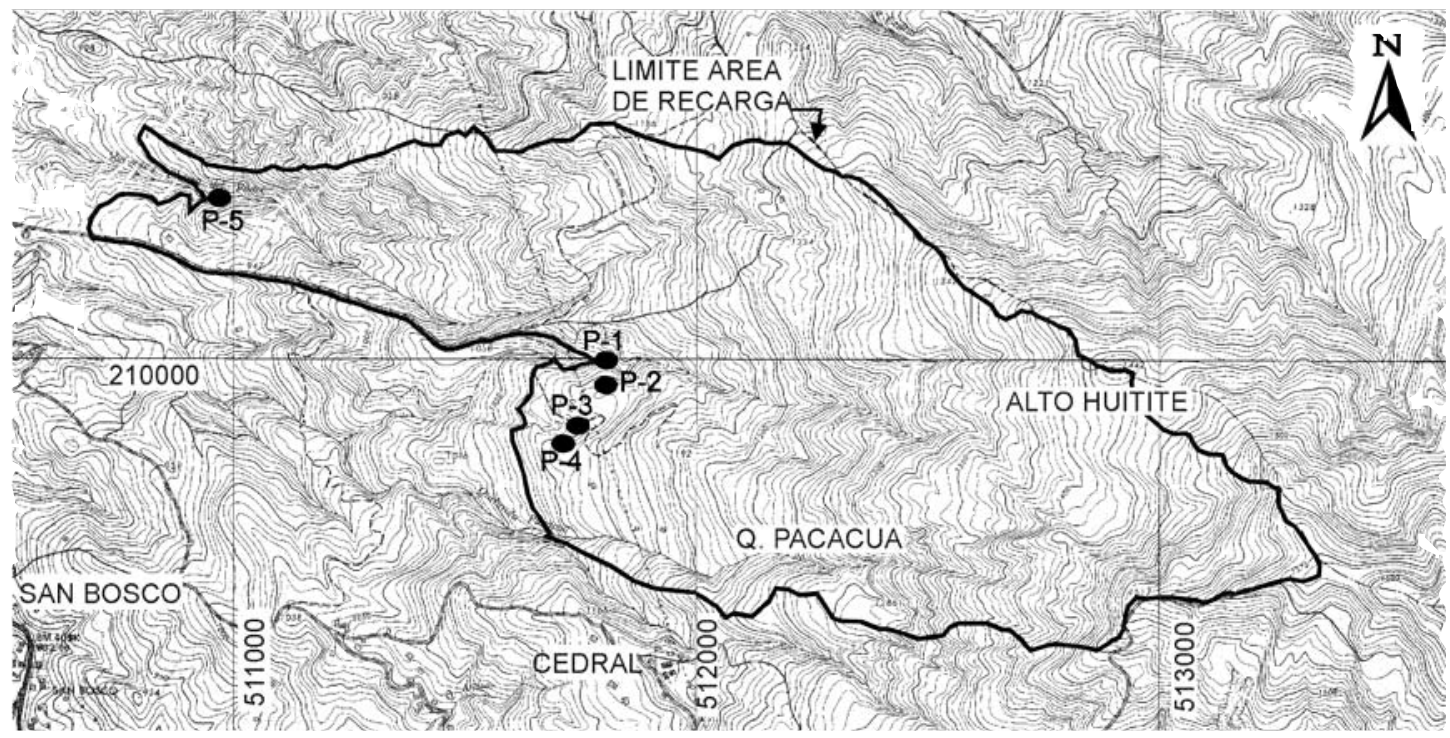

Fig. 2: Área de recarga de los manantiales estudiados en la Formación Pacacua.

compuestas por fósiles, feldespatos potásicos, plagioclasas, cuarzo, pirita, magnetita, vetas de calcita, dolomita, fragmentos calcáreos y una matriz arcillosa silícea en ocaciones ferruginosa.

\section{ÁREA DE RECARGA DE LOS MANANTIALES}

La zona de recarga de los manantiales se ha delimitado siguiendo la metodología de Losilla (1992), asumiendo que los límites de la cuenca hidrogeológica coinciden con los límites de la cuenca hidrológica, según la cual se sigue la curva de elevación topográfica más baja de la captación del manantial, a ambos lados del mismo, hasta cruzar un río importante, considerado como influente, a partir de esto se sigue por las divisorias de las subcuencas hasta unirse en su parte superior (Fig. 2 y 3 ).

El área de recarga de los manantiales estudiados de la Formación Pacacua, abarca aproximadamente $2 \mathrm{~km}^{2}$ con elevaciones topográficas que varían entre 900 hasta 1575 m.s.n.m y presenta una orientación Este-Oeste, que coincide con la dirección de buzamiento de la formación en esta área, lo cual sugiere que el flujo de agua subterránea está siendo controlado por planos de debilidad de la roca. La precipitación promedio mensual varía desde 17 hasta $465 \mathrm{~mm}$ y el uso del suelo está distribuido entre actividades agropecuarias, plantaciones de café y plantaciones de árboles frutales principalmente. Esta zona se caracteriza por temperaturas mucho más elevadas que el sector de los manantiales de la Formación Peña Negra estudiados. En el área se ha incrementado el número de desarrollos habitacionales debido a la ubicación geográfica y belleza escénica, aunque no se ha considerado la disponibilidad del recurso hídrico a mediano y largo plazo.

El área de recarga de los manantiales estudiados de la Formación Peña Negra ocupa aproximadamente $0,5 \mathrm{~km}^{2}$. Sin embargo, esta extensión puede ser mayor al considerar el buzamiento estratigráfico de la formación en este sector. Es un área que está definida por una altura entre 1680 y 1800 m.s.n.m. La precipitación promedio mensual oscila entre 9 y $394 \mathrm{~mm}$. El uso del suelo está dividido entre actividades agropecuarias, tacotales y desarrollos habitacionales. El relieve presenta amplias variaciones desde sitios con pendientes bajas $\left(<5^{\circ}\right)$ hasta pendientes fuertes 
$\left(>30^{\circ}\right)$. Debido a las condiciones climáticas, vista panorámica y ubicación geográfica del área con respecto al Valle Central, se está llevando a cabo la apertura de nuevos caminos y la remoción de materiales con el fin de impulsar la construcción de viviendas. Esto ha traido consigo la impermeabilización del suelo en algunos sectores.

\section{PRODUCCIÓN \\ DE LOS MANANTIALES}

Los manantiales analizados fueron aforados entre el 24 y 26 de febrero de 1998 y han dado como resultado una producción que varía desde 0,4 hasta 24,4 1/ min (Tabla 1). El caudal total aforado en los manantiales de la Formación
Pacacua se estimó en 30,3 1/min, que en realidad es el producto de una serie de manantiales con caudales bajos. El aforo de los manantiales en la época de verano permite visualizar a mediano o largo plazo el caudal que se esperaría en la época de menor producción (Robles,1996), lo cual puede ser utilizado como parámetro para llevar a cabo estudios de abastecimiento y demanda por parte de instituciones estatales.

La producción de los manantiales aforados en la Formación Peña Negra varía desde 0,6 hasta 6,1 1/ min. El caudal total aforado en los manantiales de la formacion Peña Negra se calculó en 8,3 1/min. Los valores de caudal se estimaron utilizando un recipiente graduado y un cronómetro para medir el volumen y el tiempo respectivamente, calculando posteriormente el caudal de cada manantial.

\section{0}

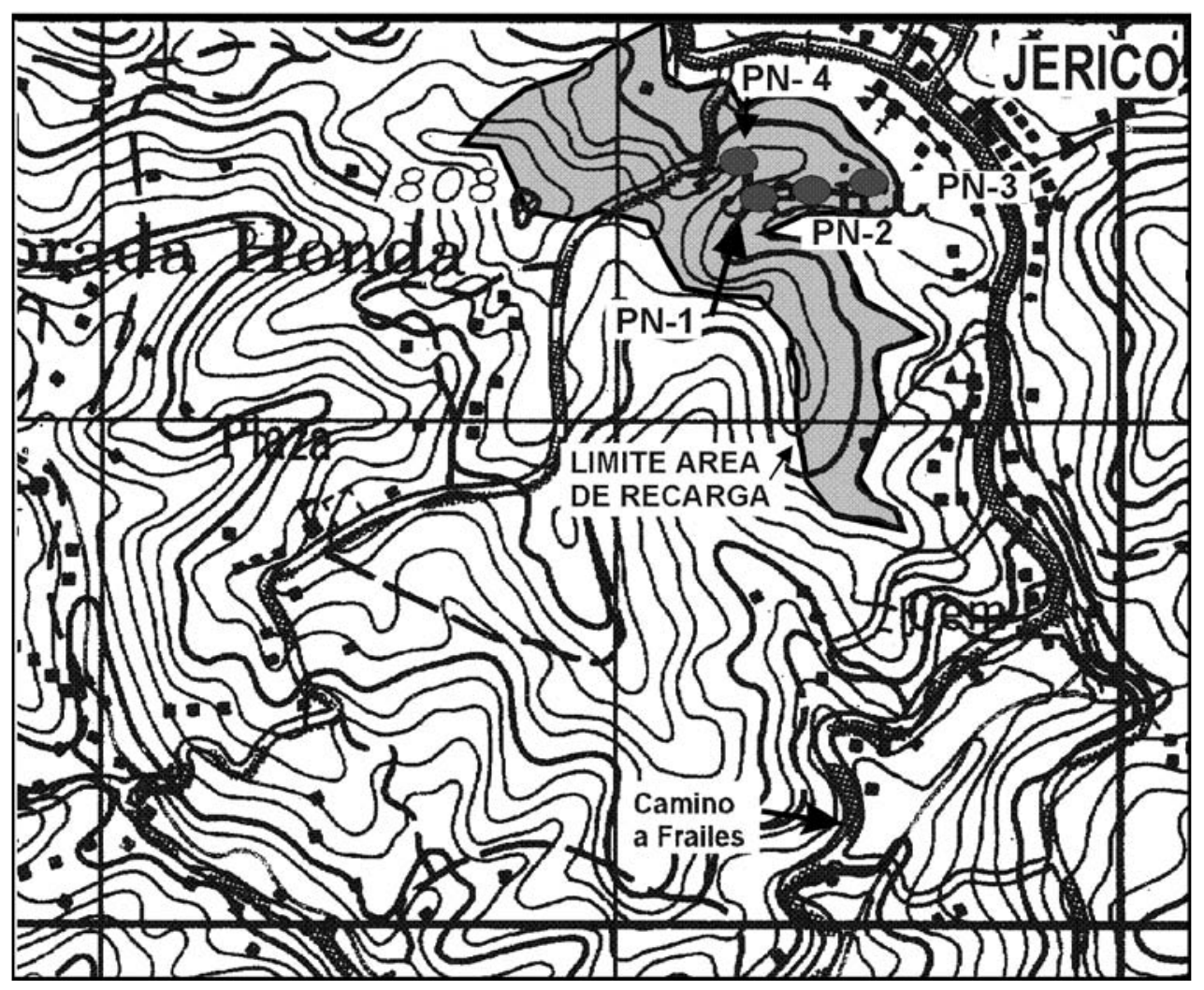

201000

Fig. 3: Área de recarga de los manantiales estudiados en la Formación Peña Negra. 
Tabla 1

Ubicación de los manantiales aforados

\begin{tabular}{|c|c|c|c|c|c|}
\hline Manantial & Latitud Norte & Latitud Sur & Altura (m.s.n.m) & Formación & Producción (1/min) \\
\hline P- 1 & 210000 & 511800 & 1090 & Pacacua & 1,1 \\
\hline P-2 & 210000 & 511770 & 1070 & Pacacua & 24,4 \\
\hline P-3 & 209000 & 511000 & 1090 & Pacacua & 0,4 \\
\hline P-4 & 209000 & 511000 & 1100 & Pacacua & No medido \\
\hline $\mathrm{P}-5$ & 210000 & 510950 & 900 & Pacacua & 4,4 \\
\hline PN- 1 & 201600 & 529400 & 1700 & Peña Negra & 0,6 \\
\hline $\mathrm{PN}-2$ & 201600 & 529500 & 1690 & Peña Negra & 0,8 \\
\hline $\mathrm{PN}-3$ & 201600 & 529600 & 1690 & Peña Negra & 6,1 \\
\hline $\mathrm{PN}-4$ & 201800 & 529300 & 1700 & Peña Negra & 0,8 \\
\hline
\end{tabular}

\section{CALIDAD FíSICO-QUíMICA Y BACTERIOLÓGICA DEL AGUA EN LA FORMACIÓN PACACUA}

Para determinar la calidad físico-química y bacteriológica del agua de los manantiales aforados se han tomado diez muestras de agua, de las cuales siete muestras se utilizaron para la evaluación de parámetros físico-químicos $\mathrm{P} 1(1,2,3), \mathrm{P} 2$ $(5,6)$, P4 (8) y P5 (9) y tres para análisis bacteriológicos P1(4), P2 (7) y P5 (10). Para el análisis de estas muestras se ha seguido la metodología de análisis sugeridos por SMWW (1995). Los valores obtenidos se han comparado con las normas de calidad del agua formuladas por el Comité Coordinador Regional de Instituciones de Agua Potable y Saneamiento de Centroamérica, Panamá y República Dominicana (CAPRE, 1994) y se ha establecido su nivel de potabilidad (Tabla 2). La concentración de los parámetros analizados presentan variaciones debidas a la heterogeneidad de la formación geológica y a que no se midieron todos los constituyentes menores y a las concentraciones relativamente bajas de los elementos. Además los manantiales no se presentan como una fuente puntual de descarga de agua, sino por el contrario como puntos dispersos y esto genera errores de muestreo. Para cuantificar el error de electroneutralidad se ha calculado el \% EPM, el cual varía de +8 a +30 , indicando valores más elevados de los cationes sobre los aniones.
De la comparación de los análisis de las muestras de agua con los valores de la norma de CAPRE se desprende que el agua de las muestras 2, 3, 6 y 9 se puede utilizar para consumo humano. Sin embargo el agua de la muestra 1 del manantial P1, la muestra 5 del manantial P2 y la muestra 8 del manantial $\mathrm{P} 4$ no es potable debido a un $\mathrm{pH}$ bajo. Por su parte la muestra 4 del manantial P1, la muestra 7 del manantial P2 y la muestra 10 del manantial P5, no son potables por la presencia de un número elevado de bacterias coliformes totales, aunque son necesarios más análisis para confirmar esta afirmación. De lo anterior se desprende que en general el agua de los manantiales no se puede utilizar para consumo humano sin el tratamiento previo, aunque son necesarios más análisis.

\section{CALIDAD FíSICO-QUíMICA Y BACTERIOLÓGICA DEL AGUA EN LA FORMACIÓN PEÑA NEGRA}

Para determinar la calidad físico-química y bacteriológica del agua en los puntos aforados dentro de la Formación Peña Negra, se tomaron 10 muestras, de las cuales 8 se utilizaron para la evaluación de parámetros físico-químicos $\mathrm{PN}-1$ $(1,2,3), \mathrm{PN}-2(5,6,7), \mathrm{PN}-3$ (9) y PN-4 (10), como se presenta en la tabla 3 y dos para análisis 


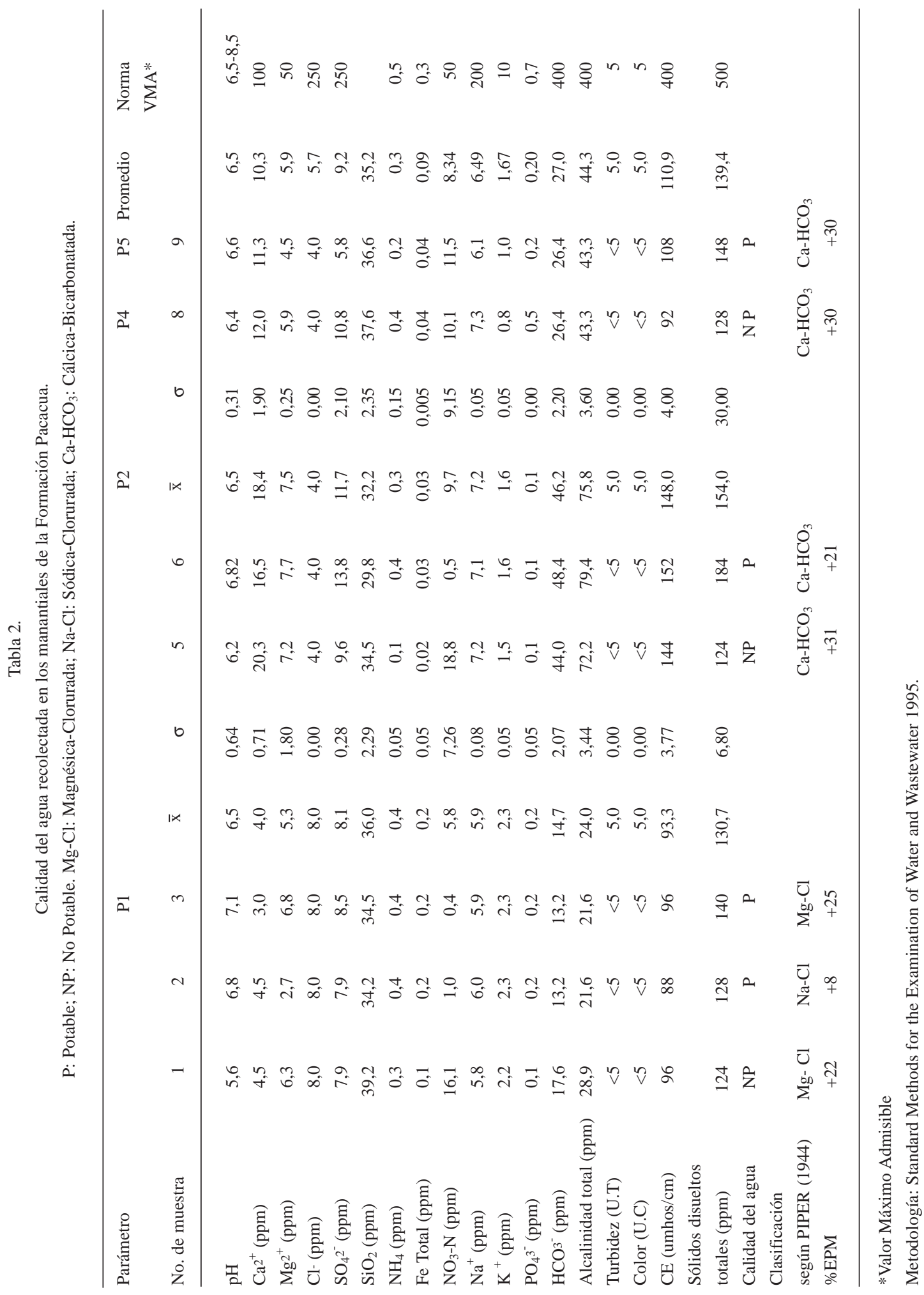




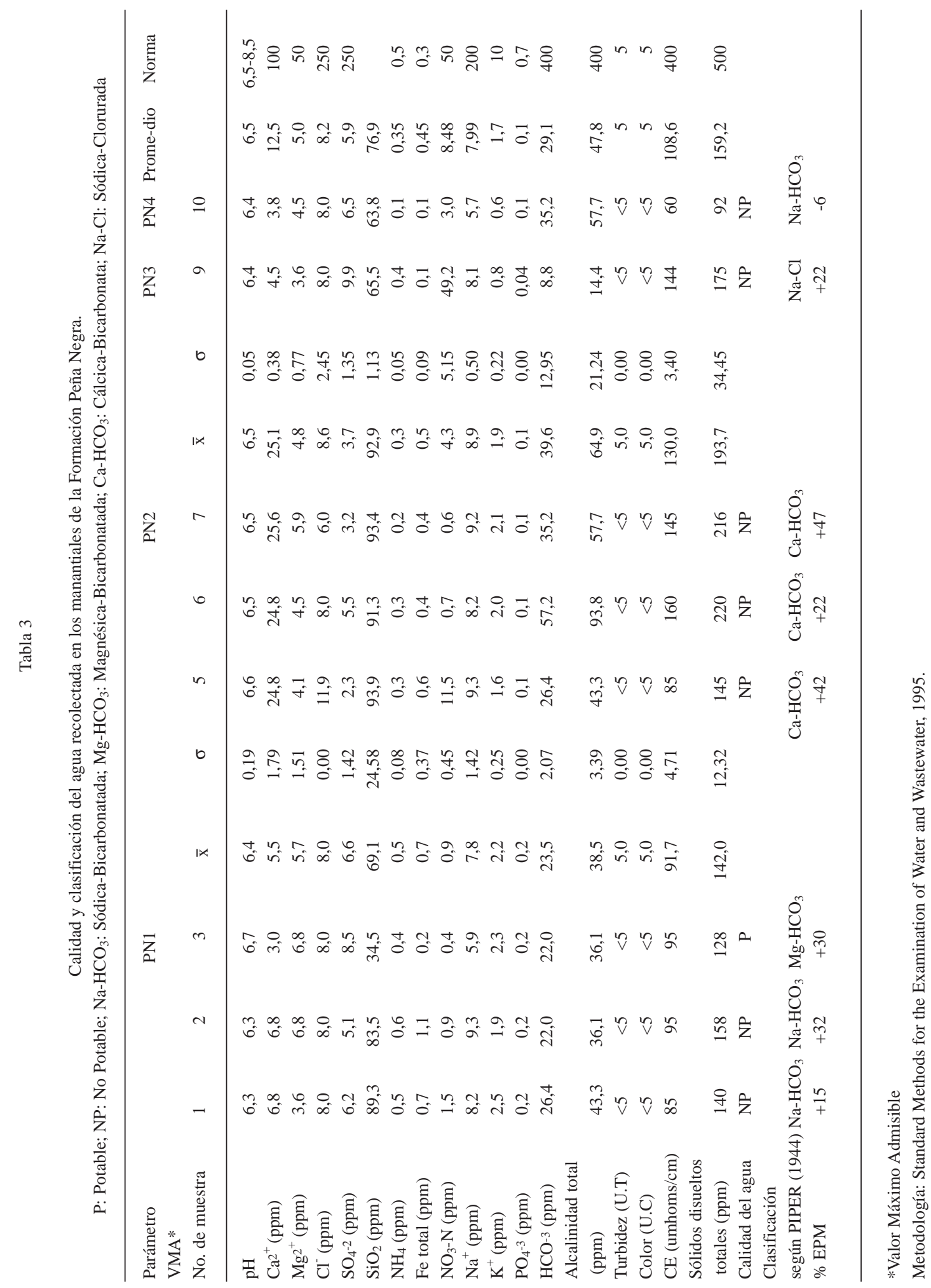




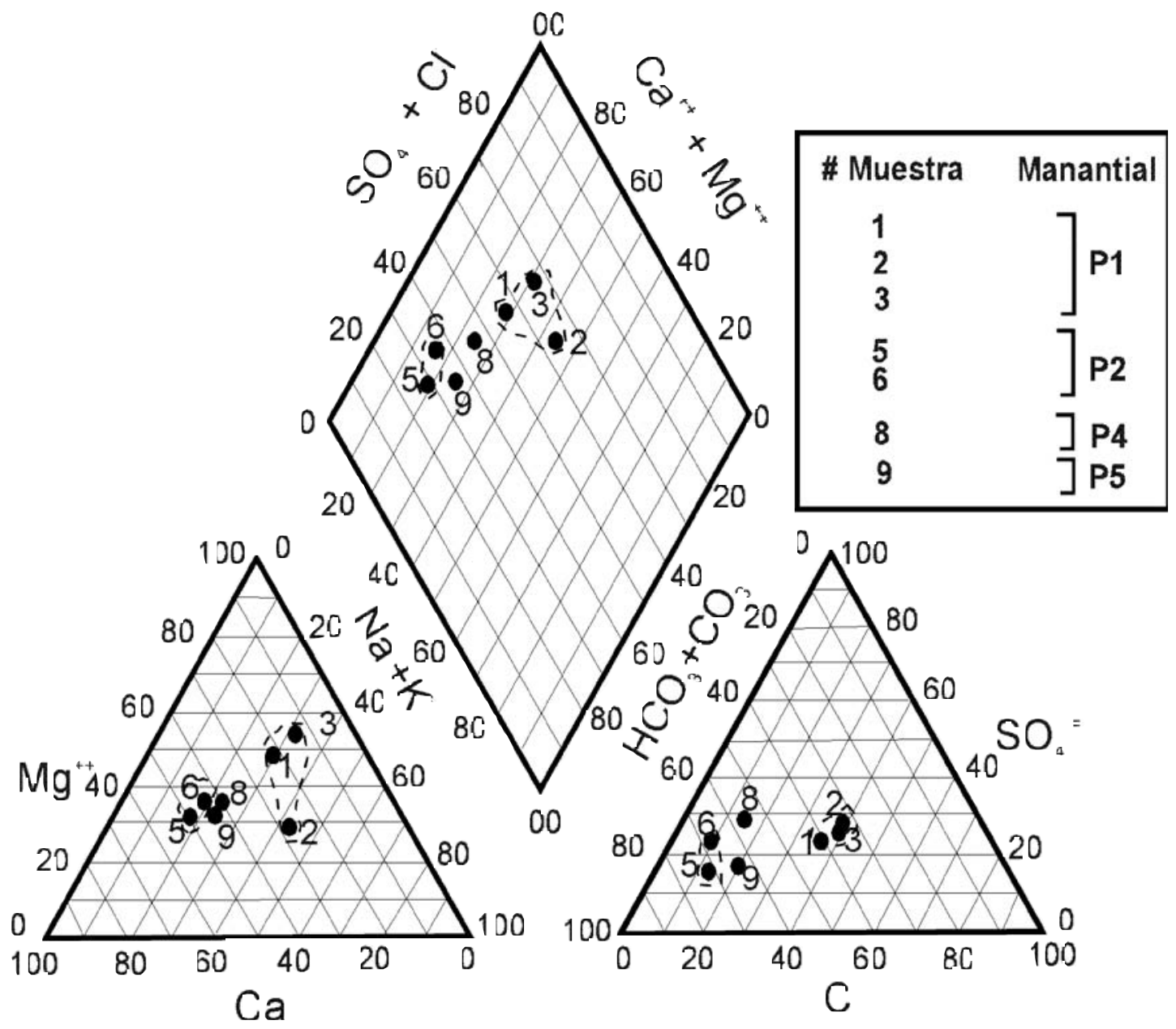

Fig. 4: Clasificación hidrogeoquímica de las muestras de agua de los manatiales de la Formación Pacacua en el diagrama de Piper.

bacteriológicos PN-1(1) y PN-2 (8). Para este grupo de muestras el error de electroneutralidad (\%EPM) varía entre $-6 \mathrm{y}+47 \%$, mostrando diferencias más amplias y predominancia de los porcentajes positivos.

De los resultados brindados por los análisis físico-químicos se desprende que el agua de las muestras 3, 5, 6 y 7 correspondientes a los manantiales PN-1 y PN-2 es potable. Sin embargo el agua de las muestras 1 y 2 del manantial PN-1, la muestra 9 del manantial PN-4 y la muestra 10 del manantial PN-5 se clasifican como no potables debido a un $\mathrm{pH}$ bajo. Por su parte las muestras 1 y 2 del manantial PN-1 y la muestra 5, 6 y 7 del $\mathrm{PN}-2$, presentan concentraciones de hierro que sobrepasan la norma, clasificándose como no potable. Desde el punto de vista bacteriológico el agua de las muestra 4 del manantial $\mathrm{PN}-1$ y de la muestra 8 del PN-2 presenta contenidos de coliformes totales que sobrepasan la norma, considerándose el agua como no potable. Al analizar los resultados se puede señalar que en términos generales el agua de los manantiales no es potable pues al menos una de las muestras no es de buena calidad. Además es necesario realizar más análisis de tipo bacteriológico para definir más exactamente el nivel de contaminación. 
CLASIFICACIÓN HIDROGEOQUÍMICA

DEL AGUA SUBTERRÁNEA

EN LA FORMACIÓN PACACUA

La clasificación hidrogeoquímica de las muestras se ha hecho por medio del diagrama triangular de Piper (1944) el cual incluye el porcentaje de los cationes $\mathrm{Na}^{+}, \mathrm{K}^{+}, \mathrm{Ca}^{+}{ }^{+} \mathrm{y} \mathrm{Mg}^{+}$y los aniones $\mathrm{CO}^{3}, \mathrm{HCO}^{3}, \mathrm{Cl}^{-}$y $\mathrm{SO}_{4}{ }^{-}$(Fig. 4). Las muestras de agua del manantial P1 presentan una composición más clorurada-magnésica comparado con P2, P4 y P5.

\section{CLASIFICACIÓN HIDROGEOQUÍMICA DEL AGUA SUBTERRÁNEA EN LA FORMACIÓN PEÑA NEGRA}

El agua de las muestras analizadas para los manantiales PN-1, PN-3 y PN-4 presenta una composición hacia el tipo sódica-bicarbonatada mientras que el agua del manantial PN-2 presenta una composición cálcica bicarbonatada (Fig. 5). En el triángulo de los aniones se observa un agrupamiento de las muestras señalando la predominancia del bicarbonato. En el triángu-

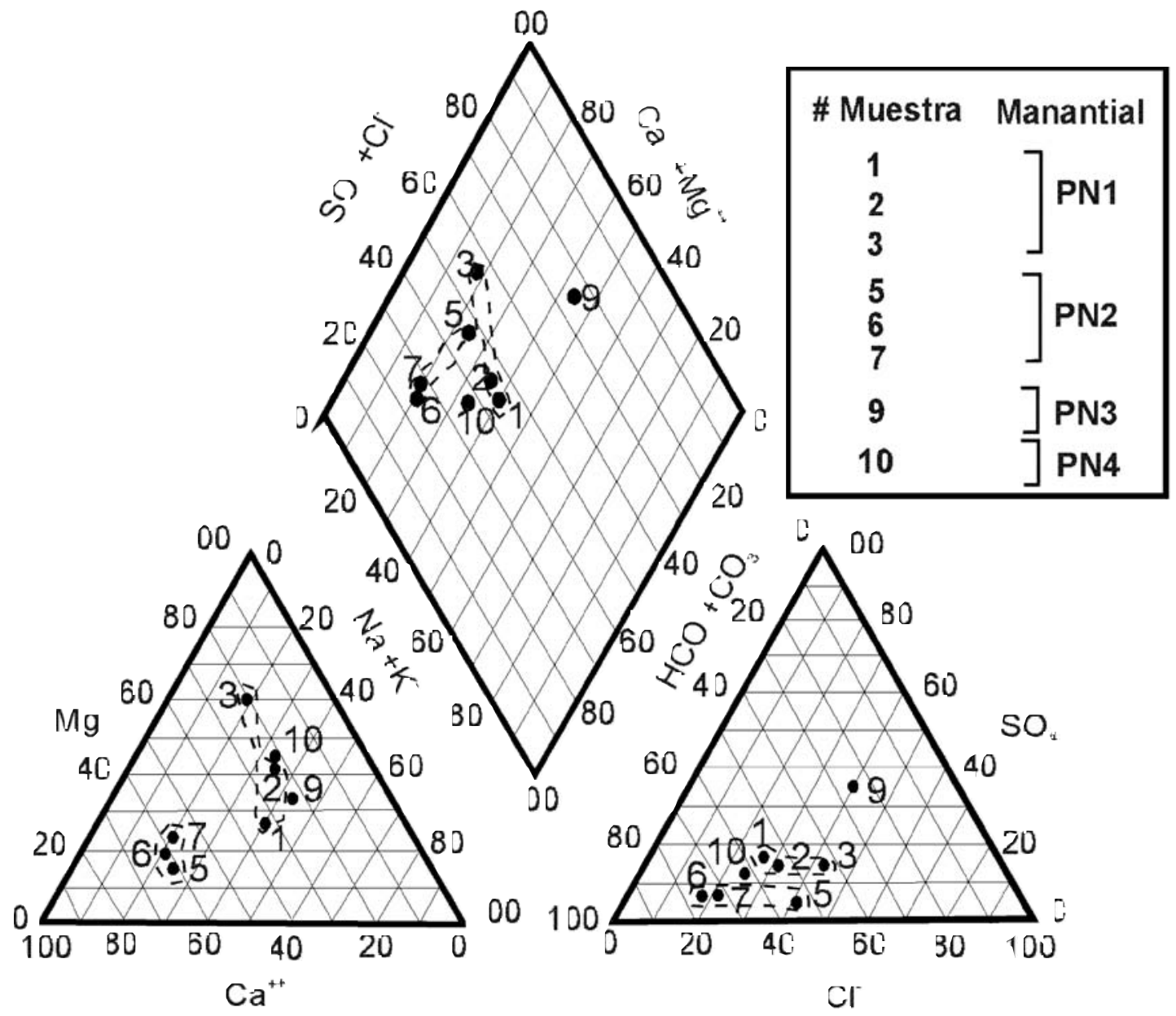

Fig. 5: Clasificación hidrogeoquímica de las muestras de agua de los manantiales de la Formación Peña Negra en el diagrama de Piper. 
lo de los cationes las muestras se encuentran más dispersas con variaciones hacia el calcio, sodio o magnesio.

Las muestras de los manantiales PN1 y PN5 muestran una composición magnésica-bicarbonatada. Las muestras del manantial PN2 tienen una tendencia cálcica-bicarbonatada la cual ocurre por la meteorización y disolución del carbonato de calcio según la ecuación (1). En PN4 el sodio y el cloruro proceden del lavado de los materiales de esta formación, que es de ambiente marino, así como de la disolución de la plagioclasa sódica según la reacción (2).

$$
\begin{aligned}
& \mathrm{CaCO}_{3}+\mathrm{H}^{+}=\mathrm{Ca}^{2+}+\mathrm{HCO}^{3^{-}} \\
& 2 \mathrm{NaAlSi}_{3} \mathrm{O}_{8}+2 \mathrm{H}^{+}+9 \mathrm{H}_{2} \mathrm{O}= \\
& \mathrm{Al}_{2} \mathrm{Si}_{2} \mathrm{O}_{5}(\mathrm{OH})_{4}+4 \mathrm{H}_{4} \mathrm{SiO}_{4}+2 \mathrm{Na}^{+}
\end{aligned}
$$

\section{CONCLUSIONES Y RECOMENDACIONES}

Las formaciones Pacacua y Peña Negra tienen un potencial hídrico subterráneo que podría suplir parte de la demanda de agua necesaria para desarrollos habitacionales ubicados al Sur o Sureste del área Metropolitana. De acuerdo a los manantiales aforados, la Formación Pacacua rinde un caudal de agua mayor que la Formación Peña Negra, lo cual ocurre por un área de recarga mayor y a características hidrogeológicas favorables de las rocas de la Formación Pacacua. Sin embargo es necesario realizar mediciones del caudal por un período de tiempo más amplio para estimar los caudales mínimos y máximos y conocer el rendimiento real de los manantiales.

Las investigaciones sobre la hidrogeoquímica realizados aquí representan una primera aproximación y no se deberían tomar como definitivas. Es necesario tomar más muestras de agua en otras épocas del año para analizar el comportamiento hidrogeoquímico. Además se debe tomar en cuenta que en varios de los manantiales no se tomaron muestras para análisis bacterioló- gicos, por lo que la contaminación por bacterias indicadoras de tipo coliformes podría ser más extensa. Por otro lado para establecer con más detalle el grado de contaminación se deberían tomar varias muestras de un mismo manantial.

El agua subterránea proveniente de las formaciones Pacacua y Peña Negra requiere de un tratamiento para controlar la contaminación bacteriológica. Así mismo la elevada concentración de hierro y el pH bajo, podrían regularse al emplear métodos de precipitación o de disolución respectivamente.

En términos generales se puede señalar que la composición química de las muestras de agua de los manantiales analizados tanto de la Formación Pacacua como la de Peña Negra es similar, como se desprende de comparar los valores promedio de los parámetros analizados. Sin embargo se presentan diferencias con respecto al sílice $\left(\mathrm{SiO}_{2}\right)$ y al hierro total. Las concentraciones de estas substancias son más elevadas en las muestras de agua de la Formación Peña Negra (76,9 y 0,45 ppm) comparadas con las de la Formación Pacacua $(35,2$ y 0,09$)$ y se debe a la presencia de algunas variedades de cuarzo, una matriz silícea y pirita en proporciones mayores en las rocas de dicha formación que en la Formación Pacacua, como lo señalan varios autores, entre ellos Alvarado (1982). Sin embargo se presentan similitudes con respecto a las concentraciones de otras substancias y elementos, que surgen de las composiciones similares en los constituyentes de las rocas.

Las muestras de agua del manantial P-1 de la Formación Pacacua presentan una clasificación hidrogeoquímica independiente con respecto a los otros manantiales con una composición tipo magnésica-clorurada. Esta diferencia se origina por la heterogeneidad de la formación. El agua de varias muestras recogidas en los manantiales de la Formación Peña Negra se caracterizan por concentraciones elevadas de hierro, que proviene de la desintegración de la pirita, la cual es mencionada por Denyer \& Arias (1991) como constituyente de esta formación. La mayoría de las muestras se definen como cálcica-bicarbonatada o sódica-bicarbonatada, sin embargo la muestra 3 del manantial PN-1 se clasifica como magnésica-bicarbonatada, separándose de la composición general de las muestras. 
Para mejorar la calidad del agua subterránea a mediano y largo plazo se deben proteger las áreas de recarga y se debe restringir la descarga de aguas negras y de aguas pluviales y el uso de agroquímicos. La construcción de nuevos caminos se debe regular y los existentes se deben cubrir con lastre y equipar con cunetas y alcantarillas. El área de las captaciones de los manantiales se debe proteger por medio de una estructura de concreto, o de materiales adecuados que impida el contacto directo de personas y animales con el agua, así como por medio de barreras que limiten el acceso del ganado, para el cual debe disponerse de abrevaderos alejados de la captación.

\section{AGRADECIMIENTOS}

Se agradece la colaboración de Jesse Stimson, profesor de la Maestría en Geología, por las sugerencias y correcciones realizadas al manuscrito. Este trabajo forma parte del proyecto de investigación 113-99-296, Manejo adecuado de los Recursos Hídricos Subterráneos inscrito ante la Vicerrectoría de Investigación de la Universidad de Costa Rica.

\section{REFERENCIAS}

ALVARADO, M.E., 1982: Estudios sedimentológicos en la Formación Pacacua (Mioceno, Costa Rica). - Tesis de Lic. (inédita), Escuela de Geología, 185 págs. San José.

ARREDONDO, S., 1994: Aguas subterráneas y fuentes termales. - En: DENYER, P. \& KUSSMAUL, S., (eds.) 1994: Atlas Geológico de la Gran Area Metropolitana, Costa Rica. - 275 págs., Ed. Tecnológica, Cartago.
CAPRE, 1994: Normas de calidad del agua para consumo humano. - 24 págs. San José.

DENYER, P.\& ARIAS, O., 1991: Estratigrafía de la región central de Costa Rica. - Rev. Geol. Amér. Central, 12: 1-59.

DENYER, P. \& ARIAS, O., 1994: Estratigrafía sedimentaria. - En: DENYER, P. \& KUSSMAUL, S., (eds.) 1994: Atlas Geológico de la Gran Area Metropolitana, Costa Rica. 275 págs., Ed. Tecnológica, Cartago.

FLORES, E., 1995: Geografía de Costa Rica. 369 págs., Ed. UNED, San José.

HERNANDEZ, J. \& VARGAS, A., 1992: Geología urbana del cantón de Escazú, provincia de San José. - Inf. Camp. Geol. 172 págs., Escuela Centroamericana de Geología.

LOSILLA, M., 1992: Mapa de fuentes de acueductos y sus áreas de recarga. - 17 págs., FUNDECOR, Heredia.

PIPER, A., 1944: A graphic procedure in the geochemical interpretation of water analyses. - Trans. Amer. Geophy. Union 25: 914-923.

ROBLES, G., 1996: Criterios de diseño y sus efectos en la operación de acueductos rurales. - Taller de capacitación para los comités administradores de acueductos rurales. 30 págs., AyA, San José.

SMWW., 1995: Standard Methods for the Examination of Water and Wastewater. 19th Edition. 